\title{
Intra-arterial treatment methods in acute stroke therapy
}

\section{Thanh N. Nguyen ${ }^{1,2 *}$, Viken L. Babikian ${ }^{1}$, Rafael Romero ${ }^{1}$, Aleksandra Pikula ${ }^{1}$, Carlos S. Kase ${ }^{1}$, Tudor G. Jovin ${ }^{3}$ and Alexander M. Norbash ${ }^{2}$}

1 Department of Neurology, Boston Medical Center, Boston University School of Medicine, Boston, MA, USA

2 Department of Radiology, Boston Medical Center, Boston University School of Medicine, Boston, MA, USA

${ }^{3}$ Stroke Institute, University of Pittsburgh Medical Center, Pittsburgh, PA, USA

\section{Edited by:}

Alex Abou-Chebl, University of Louisville School of Medicine, USA

Reviewed by:

Osama O. Zaidat, Medical College of Wisconsin/Froedtert Hospital, USA

Randall Edgell, Saint Louis University, USA

\section{*Correspondence:}

Thanh N. Nguyen, Department of Neurology, Boston Medical Center, Boston University School of

Medicine, 720 Harrison Avenue, Suite

707, Boston, MA 02118, USA.

e-mail: thanh.nguyen@bmc.org
Acute revascularization is associated with improved outcomes in ischemic stroke patients. It is unclear which method of intra-arterial intervention, if any, is ideal. Promising approaches in acute stroke treatment are likely a combination of intravenous and endovascular revascularization efforts, combining early treatment initiation with direct clot manipulation and/or PTA/stenting. In this review, we will discuss available thrombolytic therapies and endovascular recanalization techniques, beginning with chemical thrombolytic agents, followed by mechanical devices, and a review of ongoing trials. Further randomized studies comparing medical therapy, intravenous and endovascular treatments are essential, and their implementation will require the wide support and enthusiasm from the neurologic, neuroradiologic, and neurosurgical stroke communities.

Keywords: intra-arterial therapy, intra-arterial thrombolysis, mechanical embolectomy, retrieval devices, aspiration devices, angioplasty, stent

\section{INTRODUCTION}

The National Institute of Neurological Disorders and Stroke (NINDS, 1995) trial initiated a new era for recanalization therapies for acute ischemic stroke patients. In 1996, after review of the results of the NINDS study demonstrating better clinical outcome in patients receiving intravenous (IV) recombinant tissue plasminogen activator (rt-PA) compared to placebo at 3 months, the US Food and Drug Administration (FDA) approved IV rt-PA for the treatment of ischemic stroke within $3 \mathrm{~h}$ from symptom onset (NINDS, 1995). Recently, the time window for IV thrombolysis was further extended to $4.5 \mathrm{~h}$ following the ECASS 3 trial which demonstrated benefit in a more select group of patients (Hacke et al., 2008). Following the ECASS 3 trial findings, the European Stroke Organization endorsed IV thrombolysis in their 2009 Stroke Guidelines for ischemic stroke patients presenting up to the 4.5-h time window. In the United States, many stroke centers have adopted administration of IV rt-PA in this time window using similar entry criteria as the ECASS 3 trial (Davis and Donnan, 2009).

Despite extension of the time window for acute stroke therapy, IV thrombolysis presents numerous challenges; early recanalization after IV rt-PA occurs in only $30-50 \%$ of patients, it has less favorable results for proximal occlusions (del Zoppo et al., 1992; NINDS, 1995; Lee et al., 2007), and re-occlusion is frequent after IV rt-PA (Grotta et al., 2001; Alexandrov and Grotta, 2002). While many patients do not present in early time windows (Kleindorfer et al., 2008), the number needed to treat (NNT) to get one added favorable outcome increases from 2 during the first 90 min to 7 within $3 \mathrm{~h}$, and reaches 14 between 3 and $4.5 \mathrm{~h}$ (Hacke et al., 2008).

Endovascular therapy includes intra-arterial (IA) thrombolytic therapy and mechanical thrombectomy. It is an alternative treatment for acute ischemic stroke in patients who are ineligible for IV thrombolysis and who present beyond the thrombolysis time window. It is also an option for patients who do not improve after IV thrombolysis (Wolpert et al., 1993). The main advantage of IA thrombolytic therapy is that it allows direct delivery of a highly concentrated and locally delivered thrombolytic drug to the thrombus within the endorgan distribution, permitting lower total amounts of systemic thrombolytics to achieve recanalization. The other advantage is that mechanical thrombectomy may spare usage of a chemical thrombolytic entirely. Disadvantages of IA approaches include the need for a neurointerventional team, the requirement to rapidly mobilize such a team, and the added time required to obtain subselective IA access in order to reopen the occluded vessel.

The principal goal of IA stroke therapy is to safely and rapidly restore flow. There are two components required to achieve this goal: recanalizing the original or primary arterial occlusive lesion (AOL) in order to reperfuse the distal arterial bed and brain parenchyma (Tomsick, 2007). Successful recanalization has been associated with improved outcomes (Rha and Saver, 2007; Nogueira et al., 2009a). Three types of reperfusion strategies have been proposed (Nogueira et al., 2009a):

1. recanalization or antegrade reperfusion

2. global reperfusion (flow augmentation by maximizing collateral circulation, or transarterial retrograde reperfusion), and

3. transvenous retrograde reperfusion

Most endovascular therapies use recanalization or antegrade reperfusion as the mechanism for restoration of flow. In this review, we will discuss available thrombolytic therapies and endovascular recanalization techniques, beginning with chemical thrombolytic agents, followed by mechanical devices (Table 1), and a review of ongoing trials (Table 2). While not all chemical 


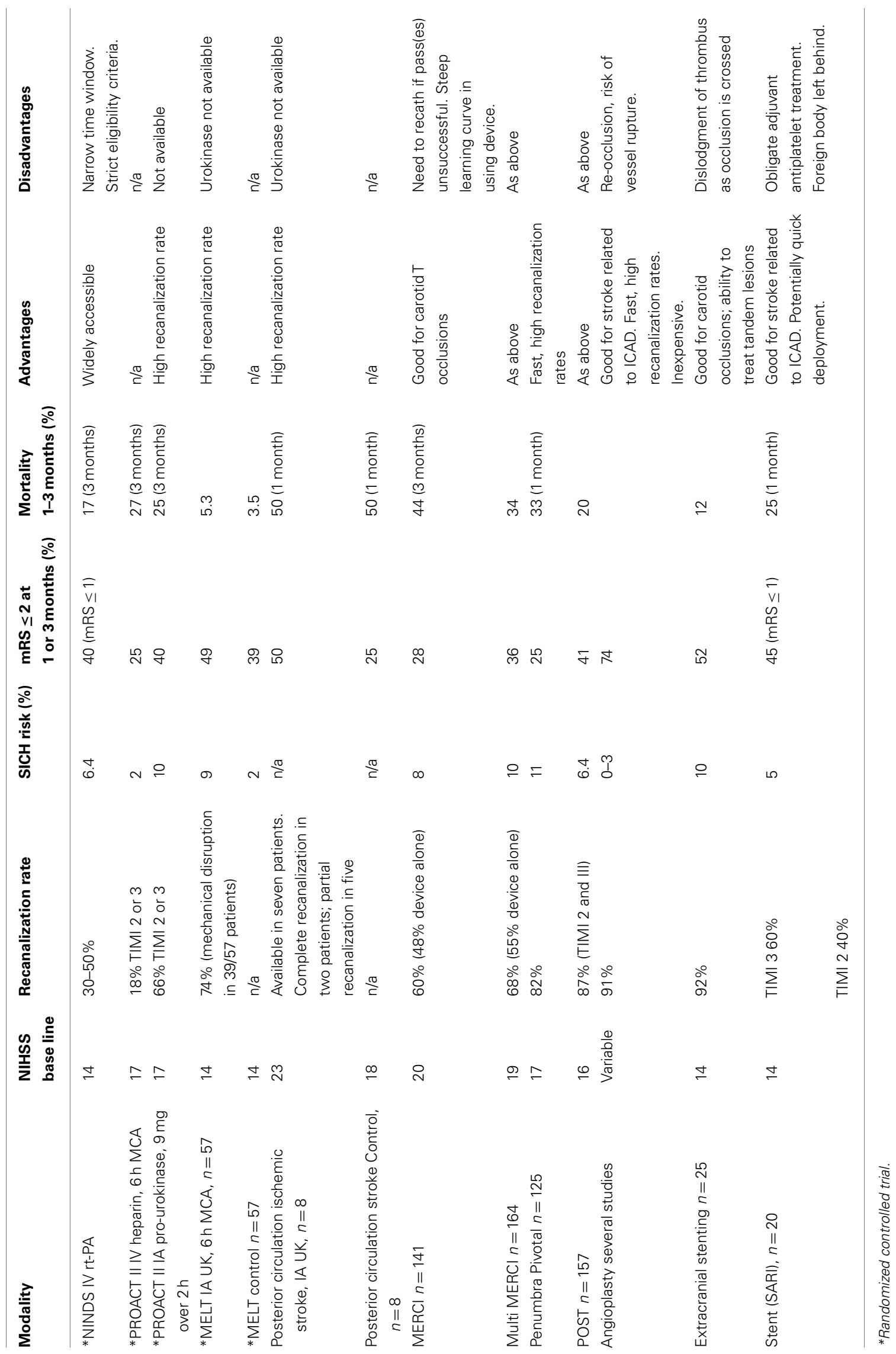


Table 2| Current randomized trials.

\begin{tabular}{|c|c|c|c|c|c|c|c|}
\hline & Goal $n$ & $\begin{array}{l}\text { Current } n \\
\text { (April 2010) }\end{array}$ & NIH & Time window (h) & Randomization & Primary outcome & Start, end date \\
\hline IMS III & 900 & 371 & $\geq 10$ & 3 & $\begin{array}{l}\text { IV t-PA vs } 0.6 \mathrm{mg} / \mathrm{kg} \\
\text { IV t-PA and IA }\end{array}$ & mRS 3 months & 2006-2014 \\
\hline THRACE & 480 & Pending & $\geq 10$ & 3 & $\begin{array}{l}\text { IV t-PA vs } 0.9 \mathrm{mg} / \mathrm{kg} \\
\text { IV t-PA and IA }\end{array}$ & mRS 3 months & 2010-2011 \\
\hline SYNTHESIS EXP & $>344$ & 170 & Open & 4.5 & $\begin{array}{l}\text { IV t-PA vs IA t-PA up } \\
\text { to } 0.9 \mathrm{mg} / \mathrm{kg} \text { (max } \\
90 \mathrm{mg})\end{array}$ & mRS 0-1, 3 months & Feb 2008, Sept 2011 \\
\hline MR CLEAN & 500 & Pending & $\geq 2$ & 6 & $\begin{array}{l}\text { IA rt-PA+/or } \\
\text { mechanical vs no IA }\end{array}$ & mRS 90 days & Jan 2010, Jan 2015 \\
\hline MR RESCUE & 120 & 77 & $\geq 6$ & 8 & $\begin{array}{l}\text { Standard vs IA with } \\
\text { MR perfusion }\end{array}$ & mRS 90 days & 2005 \\
\hline SENTIS & 515 & 515 & $5-18$ & 10 & $\begin{array}{l}\text { Standard vs aortic } \\
\text { balloon catheter }\end{array}$ & $\begin{array}{l}\text { "neurological } \\
\text { improvement;" serious } \\
\text { adverse events } 90 \text { days }\end{array}$ & 2008-2011 \\
\hline DAWN & Pending & Pending & $\geq 10$ & Indeterminate & $\begin{array}{l}\text { Standard vs IA with } \\
\text { CT perfusion or MR } \\
\text { perfusion }\end{array}$ & mRS 90 days & 2009 \\
\hline SWIFT & 200 & Pending & $8-30$ & 8 & $\begin{array}{l}\text { Merci vs Solitaire } \\
\text { device }\end{array}$ & TIMI 2 or 3 flow & Jan 2010-Dec 2011 \\
\hline
\end{tabular}

thrombolytic agents have been used or tested via IA routes, a review of chemical thrombolytics is important in the grand spectrum of acute ischemic stroke treatment.

\section{INTRA-ARTERIAL AND/OR INTRAVENOUS CHEMICAL THROMBOLYSIS}

A number of agents have been used for thrombolytic treatment of stroke including: streptokinase, urokinase, alteplase, prourokinase, reteplase, tenecteplase, and desmoteplase. In principle, these agents convert the proenzyme plasminogen to plasmin, which when activated subsequently breaks down fibrin into fibrin degradation products. The main advantage of IA over IV chemical thrombolysis is that it allows direct delivery of drug to the thrombus, and compared to mechanical techniques it requires less vessel instrumentation to reopen occluded arteries. Chemical thrombolysis also can work on distal clots, in M2, M3, and higher order branches which may be inaccessible to most mechanical devices. Despite very low systemic doses of these drugs when administered IA, the occurrence of intracranial hemorrhage ( $\mathrm{ICH}$ ) is the most feared complication. Of additional concern often a relatively long interval can elapse between initiation of drug infusion and time to vessel reopening, and such therapy failure is not uncommon.

First generation agents such as streptokinase and urokinase (withdrawn from the market) are plasminogen activators and are mainly of historical interest. Both agents have been tested in IV and IA thrombolytic trials respectively. This class of drug is not fibrin specific, thus systemic hypofibrinogenemia may occur. Streptokinase is immunogenic and may lead to drug resistance, fever, and allergic reactions. The rate of ICH is increased with streptokinase, hence it is no longer used for IV or IA stroke therapy (Nogueira et al., 2009a).
In contrast to first generation agents, second generation agents, such as alteplase and pro-urokinase are fibrin specific and are not antigenic. Alteplase or rt-PA has a similar profile to native plasminogen activator and acts by converting the proenzyme plasminogen to the active enzyme plasmin. The plasma half life of alteplase is $4-6 \mathrm{~min}$, and the dose used for IA lysis can range in practice from 1 to $60 \mathrm{mg}$. One possibly concerning feature of alteplase is that it may have neurotoxic properties including activation of metalloproteinases, which may result in increased bloodbrain barrier permeability leading to ICH and edema (Nogueira et al., 2009a). Pro-urokinase is a second generation agent which is a precursor of urokinase and has a half life of $7 \mathrm{~min}$.

Third generation thrombolytics, such as reteplase and tenecteplase, are modified forms of alteplase, have greater thrombolytic potency and longer half-lives compared to alteplase (Nogueira et al., 2009b). Compared with the second generation thrombolytics, reteplase does not bind as strongly with fibrin. In a phase I reteplase safety study, IA reteplase $(0.5,1,1.5,2$ units) with IV abciximab (platelet glycoprotein IIb/IIIa inhibitor) at a dose of $0.25 \mathrm{mg} / \mathrm{kg}$ bolus followed by $0.125 \mu \mathrm{g} / \mathrm{kg} / \mathrm{min}$ was administered to acute ischemic stroke patients presenting between 3 and $6 \mathrm{~h}$ after symptom onset. The goal was to achieve higher rates of recanalization with a medication combination using two different mechanisms of action - IA reteplase to lyse fibrin and IV abciximab to prevent platelet aggregation. Of 20 patients in this study, one symptomatic ICH was observed (1-unit tier); partial or complete recanalization was observed in 13 of $20(65 \%)$ patients (Qureshi et al., 2006).

Compared to alteplase, tenecteplase has a longer half life (17 min), higher fibrin specificity, and better resistance to plasminogen activator inhibitor-1 (Nogueira et al., 2009b). In a pilot 
study of patients presenting 3-6h after ischemic stroke onset with perfusion deficit, $0.1 \mathrm{mg} / \mathrm{kg}$ IV tenecteplase was given to 15 patients and compared with 29 patients treated with alteplase (Parsons et al., 2009). The primary outcome was reperfusion as assessed by interval reduction in the mean transit time lesion (MTT) at $24 \mathrm{~h}$ on MRI perfusion imaging, in addition to major vessel recanalization. Greater reperfusion volumes (mean 74 vs $44 \%$ for the alteplase control group) and major vessel recanalization rates $(10 / 15$ tenecteplase vs $7 / 29$ alteplase, $p=0.01)$ were seen. Despite delayed time to treatment in the tenecteplase arm, more tenecteplase patients had major neurologic improvement at $24 \mathrm{~h}$ compared to patients treated with alteplase. Although the number of stroke events was small, there were no parenchymal hematomas in the tenecteplase patients.

There are additional new generation agents which include desmoteplase, a genetically engineered version of the clotdissolving factor found in the saliva of the vampire bat desmodus rotundus (Nogueira et al., 2009b). Desmoteplase is more selective for fibrin-bound plasminogen than any other known plasminogen activator. In the Desmoteplase in Acute Ischemic Stroke (DIAS) 2 trial, MR or CT perfusion imaging was used to randomize 193 patients presenting within 3-9 h of symptom onset to two evaluated doses of desmoteplase $(90 \mu \mathrm{g} / \mathrm{g}, 125 \mu \mathrm{g} / \mathrm{kg})$ or a placebo arm. While the study did not show clinical benefit, and although the rates of symptomatic ICH were high $(3.5 \%$ for $90 \mu \mathrm{g} / \mathrm{kg}$ desmoteplase, $4.5 \%$ for $125 \mu \mathrm{g} / \mathrm{kg}$ desmoteplase, and $0 \%$ for placebo), a phase III randomized trial (DIAS 3) comparing IV desmoteplase $90 \mu \mathrm{g} / \mathrm{kg}$ to placebo is currently ongoing with a planned sample size of 320 patients triaged with MRI or CT-angiography with vessel occlusion or high-grade stenosis.

\section{IA FIBRINOLYTIC RANDOMIZED TRIALS}

The Prolyse in Acute Cerebral Thromboembolism (PROACT II) trial is a landmark study that randomized patients presenting within $6 \mathrm{~h}$ of a middle cerebral artery (MCA) occlusion to either IA pro-urokinase or IV heparin. Higher rates of recanalization were seen in the IA pro-urokinase treated cohort compared to the IV heparin treated group (66 vs $18 \%$ ) and $40 \%$ of IA patients received an mRS score $<2$ compared to $25 \%$ of controls (Furlan et al., 1999). Risk of symptomatic hemorrhage was $11 \%$ in patients receiving IA pro-urokinase compared to $3 \%$ of patients receiving heparin alone (Kase et al., 2001). An absolute risk improvement of $15 \%$ or NNT of 7 was achieved. PROACT II was pivotal as the first randomized trial to demonstrate clinical efficacy of IA therapies, extending the therapeutic window to $6 \mathrm{~h}$ for acute ischemic stroke patients. Although the success of PROACT II was insufficient to gain FDA approval for pro-urokinase, this led to a new era in IA therapy for acute ischemic stroke patients.

The Middle Cerebral Artery Embolism Local Fibrinolytic Intervention Trial (MELT), a trial performed in Japan, randomized patients presenting with MCA occlusion within $6 \mathrm{~h}$ of symptom onset to either an IA urokinase (UK) arm or a conventional treatment arm (Ogawa et al., 2007). The trial was stopped after approval of rt-PA in Japan in October 2005. While the primary endpoint of a modified Rankin Scale $(\mathrm{mRS}) \leq 1$ did not reach statistical significance, secondary analyses suggested that IA UK may offer increased likelihood of excellent functional outcomes at 90 days.

In patients with posterior circulation stroke presenting up to $24 \mathrm{~h}$, the Australian Urokinase Stroke Trial randomized 16 patients to IA urokinase (increments of 100,000 IU to maximum dose of $1,000,000 \mathrm{IU}$ ) or control (no thrombolysis). All patients were anticoagulated acutely (5000 IU heparin IA followed by IV heparin to target ptt of 60-80 for 2 days minimum), and then received oral warfarin to target INR of 1.5-2.5 for 6 months. There was some imbalance between the groups, with more severe strokes occurring in the IA arm. A good outcome was observed in four of eight patients who received IA urokinase compared with one of eight patients in the control group (MacLeod et al., 2005).

A meta-analysis comprising five randomized controlled trials (PROACT I, II, MELT, Australian Urokinase Stroke Trial) found that IA fibrinolysis was associated with increased good clinical outcomes defined as mRS 0-2 (43 vs 28\%; OR 2, 95\% CI $1.3-$ 3.1; NNT 6.8) and excellent clinical outcomes defined as mRS 0-1 (31 vs 18\%; OR 2.1; 95\% CI 1.3-3.5; NNT 7.7; Lee et al., 2007). The rate of any radiological or symptomatic hemorrhage was increased, although mortality was not higher.

\section{INTRA-ARTERIAL MECHANICAL THROMBOLYSIS}

The principal goal of mechanical thrombolysis is to restore cerebral blood flow by either removing or fragmenting obstructing thrombus. Advantages of fragmenting thrombus may include increasing surface area exposure to thrombolysis (Levy et al., 2004; Nogueira et al., 2009a). This approach may minimize or obviate the use of chemical thrombolytics, thereby decreasing the risk of $\mathrm{ICH}$ while extending the time window of intervention up to an 8-h window for the anterior circulation. Faster recanalization may be achieved with mechanical techniques as compared with infusion lysis, especially with large clot burdens and with clots containing large amounts of calcium and cholesterol (Halloran and Bekavac, 2004). Mechanical embolectomy is particularly helpful for patients who are ineligible for chemical thrombolysis, patients who are recently post-operative, coagulopathic, or who are presenting late or with an unclear time of onset. The disadvantage of mechanical devices is that almost all mechanical methods are less flexible than the smallest simple microcatheters through which thrombolytics can be introduced, especially since access pathways to occlusive lesions are tortuous. Aggressive instrumentation can lead to unfortunate complications such as dissection, perforation, vessel rupture (Nguyen et al., 2008; Malik et al., 2010), and conversion of distal emboli to more proximal larger-artery occlusions. Robust clinical outcomes demonstrating benefits of mechanical embolectomy for acute ischemic stroke have yet to be generated from randomized trials.

\section{RETRIEVAL DEVICES}

Several mechanical thrombectomy devices have been developed over the last decades. The MERCI (Mechanical Embolus Removal in Cerebral Ischemia) retriever (Concentric Medical, Mountain View, CA, USA) was the first stroke thrombectomy device approved by the FDA in 2004 and increased the practicality of mechanical thrombectomy beyond that formerly possible with snaring. More than 10,000 MERCI devices have since been used 
worldwide (Concentric Medical, personal communication). The MERCI device is an extremely flexible corkscrew-shaped device made of nitinol wire, designed to remove blood clots from the brain in patients experiencing ischemic stroke. An 8- or 9-F balloon guide catheter is placed in the internal carotid artery. The retrieval device is introduced into a 2.4-F Merci microcatheter and is advanced beyond the thrombus. The general principle of its use is that upon retrieval of the device, the balloon in the guide catheter is inflated to occlude the carotid artery with simultaneous guide catheter aspiration to prevent distal embolization of thrombus with retrieval. Recently, a 4.3-F distal access catheter (DAC) was added to navigate more distally and closer to the clot, and allow for better leverage in clot retrieval. The first generation MERCI X5 and X6 devices consisted of simple helical nitinol wire loops. The second generation L4, L5, and L6 MERCI devices added filaments to the helical nitinol coil to improve clot engagement and capture. The third generation devices ( $\mathrm{V}$ series) have variable tension in the loops (Figure 1).

The Multi MERCI trial was an international, multicenter prospective study that evaluated the combined safety of IV tPA and mechanical thrombectomy when used together. Favorable

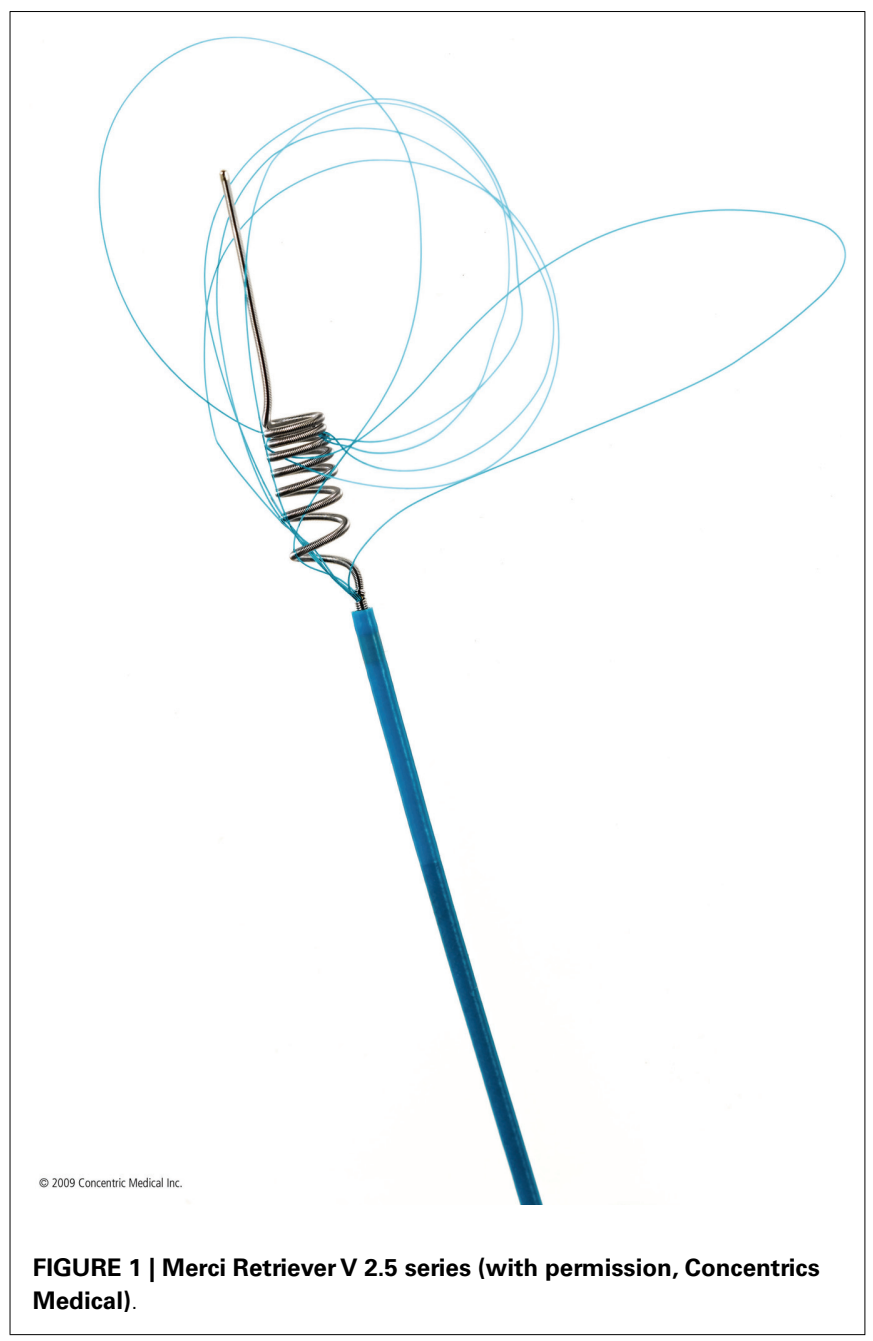

clinical outcome (mRS $0-2$ ) occurred in $36 \%$ of patients and mortality was $34 \%$. Both outcomes were related to vascular recanalization. Symptomatic ICH and procedural complications occurred in 10 and $5.5 \%$ of patients, respectively (Smith et al., 2008).

Although the MERCI device has had the largest impact to date regarding sales volume, a number of other specifically directed thrombectomy devices with various designs have also been developed. The Catch Thromboembolectomy System (Balt Extrusion, Montmorency, France) is a self-expanding basket-like device with a maximum diameter of $4 \mathrm{~mm}$, fixed to a pusher wire. This device has been tested and favorably compared with the MERCI device in animal models.

The Phenox clot retriever (Phenox, Bochum, Germany) is a flexible nitinol/platinum compound core wire resembling a bottlebrush (Henkes et al., 2006). The wire compound firmly holds perpendicularly-oriented polyamide microfilaments and carries radiodense markers on its proximal and distal end. The contour of this brush is trimmed in a conical shape with an increasing diameter distally. Animal model studies comparing the MERCI, Catch, and Phenox retriever system suggest that the Phenox retriever may be superior in preventing distal embolization because it can capture and filter the largest percentage of clot fragments (Liebig et al., 2008). Preliminary case reports in patients suggest this device holds promise as a useful supplement for thrombectomy (Henkes et al., 2006).

The Alligator Retriever (Chestnut Medical Technologies, Menlo Park, CA, USA) is a four-pronged retrieval device on a stainlesssteel wire which resembles a clawlike hand, and which closes on partial retraction into the tip of the carrying microcatheter. The Alligator Retriever is FDA approved for the retrieval of intravascular foreign bodies in the peripheral circulation and in the neurovasculature. Its use has been reported in six patients with acute MCA occlusion, with all patients achieving successful clot retrieval and improvement in NIH stroke scale (Kerber et al., 2007). Once a microcatheter is delivered to the thrombus, the retriever is pushed a few millimeters beyond the catheter tip, allowing the jaws to open. The microcatheter is then advanced to partially close the jaws and trap the clot. The whole unit is then withdrawn along with concomitant suction via a guide catheter in the internal carotid artery.

The Trevo Device (Concentric Medical) is a new thrombus retrieval system, involving a stentriever, a retrievable and nondeployable stent-like device that is designed to act as retriever. This device has received regulatory approval in Europe and Canada as of February 2010. The Solitaire device is another retrievable stenton-a-wire (EV3) designed for neurovascular disease and may be effective for acute ischemic stroke revascularization as a retrievable open-ended basket, but which has the additional feature of controlled deployment permitting the Solitaire to be left in the vessel as a conventional stent (Henkes et al., 2006).

\section{ASPIRATION DEVICES}

Several aspiration techniques and fragmentation devices have been developed for acute ischemic stroke treatment and include the Penumbra System (Bose et al., 2008; Penumbra, Alameda, CA, USA), Angiojet and manual aspiration. In contrast to retrieval devices, which are deployed distal to a thrombus for clot extraction, 
most of the aspiration techniques and fragmentation devices are placed proximal to the thrombus. The advantage to aspiration technique and devices is a lower rate of embolic events. The theory of fragmentation assumes that fragmentation methods serve two purposes; the first, as mentioned earlier, is to increase the surface area of the clot volume thereby permitting more effective thrombolysis, and the second purpose is to send the clot fragments into the more distal circulation. This distal fragmentation recognizes that leptomeningeal collateral supply is rich, serving a protective and potentially redundant blood supply to more distal circulations, and also recognizes the relatively small surface area of true clinically eloquent cortex when compared with the total surface area of the brain. Fragmentation approaches have evolved from initial wire-maceration of clot to angioplasty of clot (thromboplasty), to specialized methods for thrombofragmentation using mechanical, ultrasound, and even low-energy laser-assistance.

Manual suction or aspiration with a syringe can be used in the presence of a large vessel thrombus, such as in the internal carotid artery or basilar artery. A 10 or $20 \mathrm{cc}$ syringe can be placed at the end of a catheter or large microcatheter. This technique is inexpensive, rapid, but infrequently curative as solo technique. However, it can be used as a bridge to using another device to reopen the occluded vessel. A specific technical consideration is selecting an appropriate microcatheter which is sufficiently reinforced to present collapse or coaptation once suction is applied, in order to convey adequate suction to the tip of the microcatheter for clot retrieval.

The Penumbra System (Penumbra, Alameda, CA, USA), was FDA approved in January 2008, and designed to remove large vessel thrombi in acute ischemic stroke patients via aspiration and extraction. There are two main components of this system: a reperfusion catheter and a specially designed microwire with a distal olive known as a "separator" (Figure 2). The reperfusion catheter is connected to a suction device, and as the separator is gently pulled back and forth into the tip of the catheter there is resultant fragmentation of the clot surface with fragment aspiration into the catheter. There are now four different sizes of microcatheter, consisting of $0.054 /, 0.041 /, 0.032 /$, and 0.026 ' sized to the vessel affected. Larger microcatheter sizes are much more effective in generating higher suction. Both the Penumbra Pivotal
Stroke Trial (125 patients) and the Penumbra POST study (157 patients) evaluated the safety and effectiveness of the Penumbra system in patients with stroke symptom onset within $8 \mathrm{~h}$, and NIHSS $\geq 8$ (Penumbra POST, 2009a,b). Mean NIHSS was above 16 in both studies. Complete or partial recanalization (TIMI 2-3) was very high, achieved in over $80 \%$ of patients in both studies. Symptomatic ICH occurred in $11 \%$ in the Pivotal Trial and $6.4 \%$ in the POST study. In the POST study, good clinical outcome defined as $\mathrm{mRS} \leq 2$ was achieved in $41 \%$ of patients and a greater than 10 point improvement in the NIHSS was seen in $37 \%$ of patients.

\section{ANGIOPLASTY}

Angioplasty and stenting may be particularly advantageous when an acute vessel occlusion is related to local atherothrombotic disease. The diameter of the balloon should be slightly undersized in reference to the diameter of the occluded vessel due to the fragility of the intracranial vessels which distinctly and significantly lack an outer elastic lamina. Balloons commonly used include compliant (Hyperglide, EV3, Irvine, CA, USA) and semicompliant balloons (Gateway, Boston Scientific, Fremont, CA, USA). Balloon-assisted thromboplasty can rapidly re-establish flow, but its most feared risk is vessel rupture. Several studies have shown the high efficacy of percutaneous transluminal angioplasty (PTA) with recanalization rates of up to $90 \%$ (Ueda et al., 1998; Nakano et al., 2002; Nogueira et al., 2009a). However, its results can also be disappointing for acute cerebral occlusions (Leary et al., 2003). Re-occlusion is a common problem with balloon angioplasty, and adjunctive thrombolytics or GPIIb/IIa inhibitors are often administered in conjunction (Abou-Chebl et al., 2005).

\section{STENTS}

Initially, the use of balloon mounted stents for acute ischemic stroke revascularization resulted in high morbidity and high rates of ICH. Development of self-expandable stents for the intracranial circulation gained increasing attention and usage with the introduction of the Wingspan and Enterprise stents. The Enterprise stent (Cordis, Raynham, MA, USA) is a closed cell partially retrievable stent, which was originally developed for adjunctive
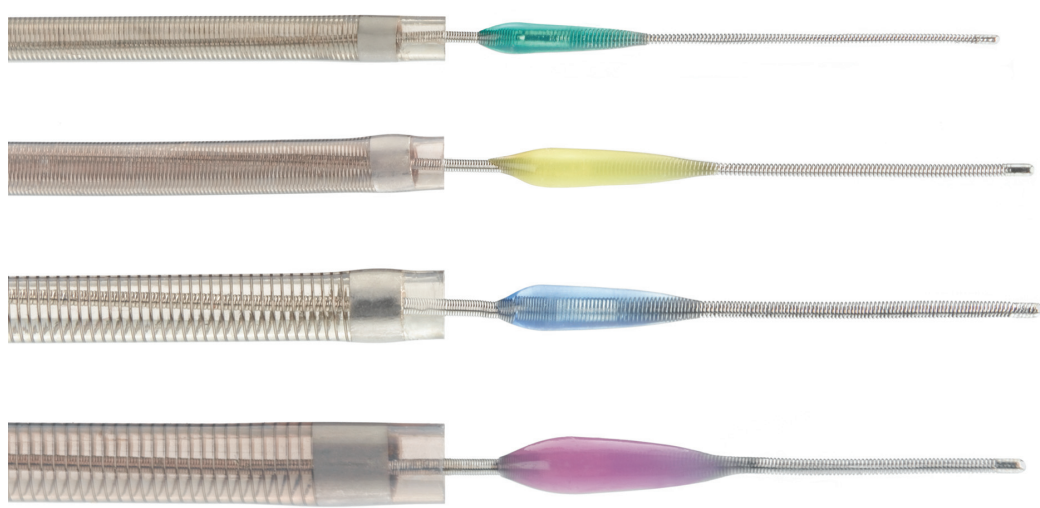

FIGURE 2 | Penumbra microcatheter and separator system (with permission, Penumbra Inc.). 
use in intracranial aneurysm treatment, and which was subsequently used off-label for acute stroke therapy in several reports (Levy et al., 2004; Kelly et al., 2008; Zaidat et al., 2008; Brekenfeld et al., 2009; Mocco et al., 2010). A retrospective multicenter series of 20 patients demonstrated revascularization in all patients $(75 \%$ with TIMI score of 3, 25\% TIMI score of 2) and improvement in NIH stroke scale in $75 \%$ of patients by four or more stroke scale points (Mocco et al., 2010). An FDA-approved pilot study of 20 patients evaluated the safety and efficacy of primary stent deployment for revascularization in acute stroke patients presenting within $8 \mathrm{~h}$. Recanalization to TIMI 3 (60\% of patients) or 2 (40\% of patients) was achieved, while there was one $(5 \%)$ symptomatic and $2(10 \%)$ asymptomatic ICH. The mRS was $\leq 1$ in 9 of 20 patients at 1 month. In the extracranial circulation, emergent stenting for acute carotid occlusion was shown to have very high recanalization rates, with rate of symptomatic $\mathrm{ICH}$ in $10 \%$ (Jovin et al., 2005). Good outcome $(\mathrm{mRS} \leq 2)$ was achieved in $13 / 25(52 \%)$ patients and mortality was $12 \%$.

Despite the high success rates and fast times achieved for recanalization with acute stenting, one of the limitations of acute stenting remains the difficulty of navigating a stent through the tortuous cerebrovascular anatomy, and as second concern is the act of leaving behind a possibly unnecessarily implanted foreign body in the patient. Retrievable and partially retrievable stents such as Solitaire (EV3), the Trevo device (Concentric), and Enterprise (Cordis) may circumvent the latter problem. Thrombosis of an acutely placed stent, obligating the patient to clopidogrel and aspirin, and sometimes GPIIbIIIa inhibitors is another disadvantage of stents. These chemical agents can increase the risk of hemorrhagic conversion of infarcts, or the risk of reperfusion hemorrhage.

\section{THE NEED FOR RANDOMIZED TRIALS}

Despite the multitude of medications and devices developed for acute ischemic stroke intervention, it is disappointing to recognize that only two large randomized trials have been completed; the PROACT I and II trials. The MELT trial was interrupted due to approval of IV rt-PA in Japan. The resistance to planning and initiating randomized trials lies in the neurointerventional community which questions whether the correct or optimal devices to randomize patients are available at present, and whether the optimal formula for patient selection using perfusion mapping have been established. The ethical concerns voiced by proceduralists who are asked to randomize patients is another significant challenge. Is it ethical to randomize a young patient with a large MCA stroke, large mismatch, and severe neurological deficit? For such a patient, a clinician may feel no clinical equipoise, and may exclude this patient from a trial. However, a 72-year-old patient presenting at $4.5 \mathrm{~h}$ from stroke onset with right MCA stroke and NIHSS of 14, ASPECTS score of 7 , could be considered to have clinical equipoise for randomization. Where equipoise exists, randomizing subjects to clinical trials is a rational and appropriate approach (Tomsick, 2007).

There is an important need for randomized controlled trials of acute stroke intervention to demonstrate the clinical benefit of our therapies. The most important measure for efficacy of any acute stroke treatment is not recanalization, but ultimately is clinical outcome (Wechsler, 2006). Belief in our therapies is not knowledge and conviction is not proof (Saver, 2006). Our initial hypotheses have been proven wrong many times in our therapies for cerebrovascular disease. Two examples of flawed hypotheses include the EC/IC bypass study which showed no benefit from performing MCA-STA bypass in patients with carotid occlusion, and the WARRS study which showed absence of benefit with warfarin treatment compared to aspirin for secondary prevention of stroke.

\section{ONGOING AND FUTURE TRIALS IMS III}

The Interventional Management Stroke Trial III is a NIH funded phase III randomized multicenter trial evaluating acute ischemic stroke patients presenting within $3 \mathrm{~h}$, comparing IV rtPA $(0.9 \mathrm{mg} / \mathrm{kg})$ to reduced dose IV rt-PA $(0.6 \mathrm{mg} / \mathrm{kg})$ followed by IA therapy, with primary outcome measure of $\mathrm{mRS}$ at 3 months (Khatri et al., 2008). Despite the recent results of the ECASS 3 trial (Hacke et al., 2008), there time window for IV t-PA was study inclusion was not extended to the 4.5-h window. As of April 2010, 371 of 900 patients have been recruited from 50 sites. The trial plans to expand to Europe in the summer of 2010. The target for trial completion is 2014 (Khatri, personal communication).

\section{MR RESCUE}

The Magnetic Resonance and Recanalization of Stroke Clots Using Embolectomy (MR RESCUE) study is a NIH funded trial evaluating whether mechanical embolectomy with the MERCI or Penumbra device is superior to standard medical management of acute ischemic stroke presenting within $8 \mathrm{~h}$ of stroke onset. Patients treated with IV t-PA up to $4.5 \mathrm{~h}$ from symptom onset with persistent vessel occlusion on post-treatment MRI may also be included. The study aims to identify patients who may benefit from intervention using MRI perfusion imaging.

\section{SYNTHESIS}

SYNTHESIS is the first randomized controlled trial comparing IAT to IVT with alteplase in acute ischemic stroke within $4.5 \mathrm{~h}$ of ischemic stroke onset. The study aims to evaluate the proportion of independent survivors at 3 months. Preliminary data suggests that rapid initiation of IA thrombolysis is a safe and feasible alternative to IV thrombolysis in acute ischemic stroke (Ciccone et al., 2010). The study began enrollment February 2008 and will end September 2011. As of March 2010 almost 50\% of the target patient sample has been recruited (goal is at least 172 patients per arm; A. Ciccone, personal communication).

\section{MR CLEAN}

MR CLEAN is a multicenter randomized clinical trial of endovascular treatment of acute ischemic stroke in the Netherlands. The null hypothesis for this study is that endovascular treatment for acute ischemic stroke with onset less than $6 \mathrm{~h}$ in patients with a symptomatic proximal arterial occlusion leads to a similar distribution of functional outcomes as standard treatment. The primary outcome studied is the modified Rankin scale at 90 days. A goal of 500 patients is intended for recruitment, to be completed over 4 years. As of April 2010, the study awaits medical ethics approval (Dippel, personal communication). 


\section{RETRIEVE}

Randomized Trial of Endovascular Treatment of Acute Ischemic Stroke vs Medical Management was meant to be a multicenter international prospective randomized controlled trial comparing mechanical thrombectomy using the MERCI retriever with best medical therapy (with or without IV thrombolysis) within $8 \mathrm{~h}$ of stroke symptom onset. This study was funded by Concentric Medical, but unfortunately has been placed on hold (Concentric Medical, personal communication) for two reasons. The FDA objected to including IA thrombolytic in the intervention arm and four new national-sponsored randomized controlled trials in Europe emerged, which would directly compete with RETRIEVE (Concentrics, personal communication).

\section{SWIFT}

The Solitaire With the Intention for Thrombectomy (SWIFT) Study is a randomized study which aims to demonstrate equivalence of the SOLITAIRE ${ }^{\mathrm{TM}}$ FR Revascularization Device with the MERCI Retrieval System in patients with acute ischemic stroke presenting within $8 \mathrm{~h}$ of symptom onset and NIHSS 8-30. The primary objective is to measure arterial recanalization of the occluded target vessel as measured by TIMI score of 2 or 3 without any symptomatic $\mathrm{ICH}^{1}$.

\section{DAWN}

In patients with unclear-onset or wake-up strokes, preliminary data suggest that IV or IA thrombolysis may be safely applied based on MRI criteria (positive perfusion-diffusion mismatch and absence of well-developed fluid-attenuated inversion recovery

\footnotetext{
${ }^{1}$ www.clinicaltrials.gov
}

\section{REFERENCES}

Abou-Chebl, A., Bazjer, C. T., Krieger, D. W., Furlan, A. J., and Yadav, J. S. (2005). Multimodal therapy for the treatment of severe ischemic stroke combining GPIIb/IIa antagonists and angioplasty after failure of thrombolysis. Stroke 36, 2286-2288.

Alexandrov, A. V., and Grotta, J. C. (2002). Arterial reocclusion in stroke patients treated with intravenous tissue plasminogen activator. Neurology 59, 862-867.

Bose, A., Henkes, H., Alfke, K., Reith, W., Mayer, T. E., Berlis, A., Branca, V., Sit, S. P., for the Penumbra Phase 1 Stroke Trial Investigators. (2008). The penumbra system: a mechanical device for the treatment of acute stroke due to thromboembolism. AJNR Am. J. Neuroradiol. 29, 14091413.

Brekenfeld, C., Schroth, G., Mattle, H. P., Do, D. D., Remonda, L., Mordasini, P., Arnold, M., Nedeltchev, K., Meier, N., and Gralla, J. (2009). Stent placement in acute cerebral artery occlusion: use of a self-expandable intracranial stent for acute stroke treatment. Stroke 40, 847-852.

Cho, A. H., Sohn, S., Han, M. K., Lee, D. H., Kim, J. S., Choi, C. G., Sohn, C. H., Kwon, S. U., Suh, D. C., Kim, S. J. Bae, H. J., and Kang, D. W. (2008). Safety and efficacy of MRI-based thrombolysisin unclear-onsetstroke. Cerebrovasc. Dis. 25, 572-579.

Ciccone, A., Valvassori, L., Ponzio, M., Ballabio, E., Gasparotti, R., Sessa, M., Scomazzoni, F., Tiraboschi, P., Sterzi, R., the SYNTHESIS Investigators. (2010). Intra-arterial or intravenous thrombolysis for acute ischemic stroke? The SYNTHESIS pilot trial. J. Neurointerv. Surg. 2, 74-79.

Davis, S. M., and Donnan, G. A. (2009). 4.5 hours. The new time window for tissue plasminogen activator in stroke. Stroke 40, 2266-2267.

del Zoppo, G. J., Poeck, K., Pessin, M. S., Wolpert, S. M., Furlan, A. J., Ferbert, A., Alberts, M. J., Zivin, J. A., Wechsler, L., and Busse, O.

changes of acute diffusion lesions; Cho et al., 2008). The DWI and CTP Assessment in the Triage of Wake-Up and Late Presenting Strokes Undergoing Neurointervention trial is evaluating whether MR perfusion or CTP based endovascular treatment in patients with wake-up and late presenting strokes is as safe and effective as standard endovascular treatment performed within $8 \mathrm{~h}$ of symptom onset (phase I) and leads to improved outcomes when compared with best medical treatment (phase II, randomized controlled trial; Nogueira et al., 2009a,2009b).

\section{SENTIS}

Partial aortic occlusion may increase cerebral perfusion by increasing cerebral collateral recruitment and salvage of penumbra tissue. SENTIS (Safety and Efficacy of NeuroFlo for Treatment of Ischemic Stroke) was a randomized, controlled multicenter trial designed to demonstrate the safety and efficacy of the NeuroFlo treatment compared to standard medical care in ischemic stroke patients presenting within $10 \mathrm{~h}$ of onset (Shuaib et al., 2010). Preliminary results of the trial were presented at the 2010 International Stroke Conference and did not show benefit to the device.

\section{CONCLUSION}

Acute revascularization is associated with improved outcomes in ischemic stroke patients. It is unclear which method of IA intervention, if any, is ideal. Promising approaches in acute stroke treatment are likely a combination of IV and endovascular revascularization efforts, combining early treatment initiation with direct clot manipulation and/or PTA/stenting (Gupta et al., 2006). Further randomized studies comparing medical therapy, IV and endovascular treatments are essential, and their implementation will require the wide support and enthusiasm from the neurologic, neuroradiologic and neurosurgical stroke communities.

(1992). Recombinant tissue plasminogen activator in acute thrombotic and embolic stroke. Ann. Neurol. 32, 78-86.

Furlan, A., Higashida, R., Wechsler, L., Gent, M., Rowley, H., Kase, C., Pessin, M., Ahuja, A., Callahan, F., Clark, W. M., Silver, F., and Rivera, F. (1999). Intra-arterial prourokinase for acute ischemic stroke. The PROACT II study: a randomized controlled trial. Prolyse in acute cerebral thromboembolism. JAMA 282, 2003-2011.

Grotta, J. C., Welch, K. M., Fagan, S. C., Lu, M., Frankel, M. R., Brott, T., Levine, S. R., and Lyden, Pd. (2001). Clinical deterioration following improvement in the NINDS rtPA stroke trial. Stroke 32, 661-668.

Gupta, R., Vora, N. A., Horowitz, M. B., Tayal, A. H., Hammer, M. D., Uchino, K., Levy, E. I., Wechsler, L. R., and Jovin, T. G. (2006). Multimodal reperfusion therapy for acute ischemic stroke: factors predicting vessel recanalization. Stroke 37, 986990.

Hacke, W., Kaste, M., Bluhmki, E., Brozman, M., Dávalos, A., Guidetti, D., Larrue, V., Lees, K. R., Medeghri, Z., Machnig, T., Schneider, D., von Kummer, R., Wahlgren, N., and Toni, D. (2008). Thrombolysis with alteplase 3 to 4.5 hours after acute ischemic stroke. N. Engl. J. Med. 359, 1317-1329.

Halloran, J. I., and Bekavac, I. (2004). Unsuccessful tissue plasminogen activator treatment of acute stroke caused by a calcific embolus. J. Neuroimaging 14, 385-387.

Henkes, H., Reinartz, J., Lowens, S., Miloslavski, E., Roth, C., Reith, W. and Kuhne, D. (2006). A device for fast mechanical clot retrieval from intracranial arteries (Phenox Clot Retriever). Neurocrit. Care 5, 134-140.

Jovin, T. G., Gupta, R., Uchino, K., Jungreis, C. A., Wechsler, L. R., Hammer, M. D., Tayal, A., and Horowitz, M. B. (2005). Emergent stenting of 
extracranial internal carotid artery occlusion in acute stroke has a high revascularization rate. Stroke 36, 2426-2430.

Kase, C. S., Furlan, A. J., Wechsler, L. R., Higashida, R. T., Rowley, H. A., Hart, R. G., Molinari, G. F., Frederick, L. S., Roberts, H. C., Gebel, J. M., Sila, C. A., Schulz, G. A., Roberts, R. S., and Gent, M. (2001). Cerebral hemorrhage after intra-arterial thrombolysis for ischemic stroke: the PROACT II trial. Neurology 57, 1603-1610.

Kelly, M. E., Furlan, A. J., and Fiorella, D. (2008). Recanalization of an acute middle cerebral artery occlusion using a self-expanding, reconstrainable, intracranial microstent as a temporary endovascular bypass. Stroke 39, 1770-1773.

Kerber, C. W., Wanke, I., Bernard, J., Woo, H. H., Liu, M. W., and Nelson, P. K. (2007). Rapid intracranial clot removal with a new device: the alligator retriever. AJNR Am. J. Neuroradiol. 28, 860-863.

Khatri, P., Hill, M. D., Palesch, Y. Y., Spilker, J., Jauch, E. C., Carrozzella, J. A., Demchuk, A. M., Martin, R., Mauldin, P., Dillon, C., Ryckborst, K. J., Janis, S., Tomsick, T. A., Broderick, J. P., for the IMS III Investigators. (2008). Methodology of the Interventional Management of Stroke III Trial. Int. J. Stroke 130-137.

Kleindorfer, D., Lindsell, C. J., Brass, L., Koroshetz, W., and Broderick, J. P. (2008). National US estimates of recombinant tissue plasminogen activator use: ICD-9 codes substantially underestimate. Stroke 39, 924-928.

Leary, M. C., Saver, J. L., Gobin, Y. P., Jahan, R., Duckwiler, G. R., Vinuela, F., Kidwell, C. S., Frazee, J., and Starkman, S. (2003). Beyond tissue plasminogen activator: mechanical intervention in acute stroke. Ann. Emerg. Med. 41, 838-846.

Lee, K. Y., Han, S. W., Kim, S. H., Nam, H. S., Ahn, S. W., Kim, D. J., Seo, S. H., Kim, D. I., and Heo, J. H. (2007). Early recanalization after intravenous administration of recombinanttissueplasminogenactivator as assessed by pre- and post-thrombolytic angiography in acute ischemic stroke patients. Stroke 38, 192-193.

Levy, E. I., Kim, S. H., Bendok, B. R., Boulos, A. S., Xavier, A. R., Yahia, A. M., Qureshi, A. I., Guterman, L. R., and Hopkins, L. N. (2004). "Interventional neuroradiolgic therapy," in Stroke: Pathophysiology, Diagnosis, and Management, 4th Edn. eds J. P. Mohr, D. W. Choi, J. C. Grotta,
B. Weir, and P. A. Wolf (Philadelphia: Churchill Livingstone).

Liebig, T., Reinartz, J., Hannes, R., Miloslavski, E., and Henkes, H. (2008). Comparative in vitro study of five mechanical embolectomy systems: effectivenss of clot removal and risk of distal embolization. $\mathrm{Neu}$ roradiology 50, 43-52.

Macleod, M. R., Davis, S. M., Mitchell, P. J., Gerraty, R. P., Hankey, F. G., Stewart-Wynne, E. G., Rosen, D., McNeil, J. J., Bladin, C. F., Chambers, B. R., Herkes, G. K., Young, D., and Donnan, G. A. (2005). Results of a multicentre, randomized controlled trial of intra-arterial urokinase in the treatment of acute posterior circulation ischaemic stroke. Cerebrovasc. Dis. 20, 12-17.

Malik, A. M., Aleu, A., Lin, R., Ranawat, N. S., Vora, N. A., Jankowitz, B., Jumaa, M., Zaidi, S. F., Kanaan, H., Kostov, D. B., Reddy, V. K., Hammer, M. D., Uchino, K., Gupta, R., Wechsler, L. R., Horowitz, M. B., and Jovin, T. G. (2010). Incidence, predictors, and outcomes of intracranial vessel perforation during endovascular therapy for acute ischemic stroke. Stroke 41, 108.

Mocco, J., Hanel, R. A., Sharma, J., Hauck, E. F., Snyder, K. V., Natarajan, S. K., Llinfante, I., Siddiqui, A. H., Hopkins, L. N., Boulos, A. S., and Levy, E. I. (2010). Use of a vascular reconstruction device to salvage acute ischemic occlusions refractory to traditional endovascular recanalization methods. J. Neurosurg. 112, 557-562.

Nakano, S., Iseda, T., Yoneyama, T., Kawano, H., and Wakisaka, S. (2002). Direct percutaneous transluminal angioplasty for acute middle cerebral artery trunk occlusion: an alternative option to intra-arterial thrombolysis. Stroke 33, 2872-2876.

Nguyen, T. N., Lanthier, S., and Roy, D. (2008). Iatrogenic arterial perforation during acute stroke interventions. AJNR Am. J. Neuroradiol. 29, 974-975.

Nogueira, R. G., Liebeskind, D. S., Sung, G., Duckwiler, G., and Smith, W. S., MERCI; Multi MERCI Writing Committee. (2009a). Predictors of good clinical outcomes, mortality, and successful revascularization in patients with acute ischemic stroke undergoing thrombectomy: pooled analysis of the Mechanical Embolus Removal in Cerebral Ischemia (MERCI) and Multi MERCI Trials. Stroke 40, 3777-3783.

Nogueira, R. G., Schwamm, L. H., and Hirsch, J. A. (2009b). Endovascular approaches to acute stroke, Part 1: drugs, devices, and data. AJNR Am. J. Neuroradiol. 30, 649-661.

Nogueira, R. G., Yoo, A. J., Buonanno, F. S., and Hirsch, J. A. (2009c). Endovascular approaches to acute stroke, Part 2: a comprehensive review of studies and trials. AJNR Am. J. Neuroradiol. 30, 859-875.

Ogawa, A., Mori, E., Minematsu, K. Taki, W., Takahashi, A., Nemoto, S., Miyamoto, S., and Sasaki, M., Inoue, T., for the MELT Japan Study Group. (2007). Randomized trial of intraarterial infusion of urokinase within 6 hours of middle cerebral artery stroke. Stroke 38, 2633-2639.

Parsons, M. W., Miteff, F., Bateman, G. A., Spratt, N., Loiselle, A., Attia, J., and Levi, C. R. (2009). Acute ischemic stroke: imagingguided tenecteplase treatment in an extended time window. Neurology 72, 915-921.

Penumbra Pivotal Stroke Trial Investigators. (2009a). Penumbra Pivotal Stroke Trial. Safety and effectiveness of a new generation of mechanical devices for clot removal in intracranial large vessel occlusive disease. Stroke 40, 2761-2768.

Penumbra POST. (2009b). A Multicenter Real World Look at Penumbra System Results. Boca Raton, FL; Society of Neurointerventional Surgery, Oral Presentation.

Qureshi, A. I., Harris-Lane, P., Kirmani, J. F., Janjua, N., Divani, A. A., Mohammad, Y. M., Suarez, J. I., and Montgomery, M. O. (2006). Intraarterial reteplase and intravenous abciximab in patients with acute ischemic stroke: an open-label, doseranging, phase I study. Neurosurgery 59, 789-796.

Rha, J. H., and Saver, J. L. (2007). The impact of recanalization on ischemic stroke outcome: a metaanalysis. Stroke 38, 967-973.

Saver, J. L. (2006). Does the Merci Retriever work? Stroke 37, 13401341.

Shuaib, A., Schellinger, P., Shownkeen, H., Rutledge, N., Molina, C., Concha, M., and Bernardini, G. L. (2010). "SENTIS: a multi-center randomized trial evaluating cerebral perfusion augmentation via partial aortic occlusion in acute ischemic stroke," in International Stroke Conference, San Antonio, TX.

Smith, W. S., Sung, G., Saver, J., Budzik, R., Duckwiler, G., Liebeskind, D. S., Lutsep, H. L., Rymer, M. M., Higashida, R. T., Starkman, S., and Gobin, Y. P., and for the Multi MERCI Investigators. (2008).
Mechanical thrombectomy for acute ischemic stroke: final results of the multi MERCI trial. Stroke 39, 1205 1212.

The National Institute of Neurological Disorders and Stroke rt-PA Stroke Study Group. (1995) Tissue plasminogen activator for acute ischemic stroke. N. Engl. J. Med. 333, 1581-1587.

Tomsick, T. (2007). TIMI, TIBI, TICI: I came, I saw, I got confused. AJNR Am. J. Neuroradiol. 28, 382-384.

Ueda, T., Sakaki, S., Nochide, I., Kumon, Y., Kohno, K., and Ohta, S. (1998). Angioplasty after intraarterial thrombolysis for acute occlusion of intracranial arteries. Stroke 29, 2568-2574.

Wechsler, L. R. (2006). Does the Merci retriever work? Against. Stroke 37, 1341-1342.

Wolpert, S. M., Bruckmann, H., Greenlee, R., Wechsler, L., Pessin, M. S., and del Zoppo, G. J. (1993). Neuroradiologic evaluation of patients with acute stroke treated with recombinant tissue plasminogen activator: the rtPA Acute Stroke Study Group. AJNR Am. J. Neuroradiol. 14, 3-13.

Zaidat, O. O., Wolfe, T., Hussain, S. I., Lynch, J. R., Gupta, R., Delap, J., Torbey, M. T., and Fitzsimmons, B. F. (2008). Interventional acute ischemic stroke therapy with intracranial self-expanding stent. Stroke 39, 2392-2395.

Conflict of Interest Statement: The authors declare that the research was conducted in the absence of any commercial or financial relationships that could be construed as a potential conflict of interest.

Received: 10 November 2010; paper pending published: 31 January 2011; accepted: 07 February 2011; published online: 08 March 2011.

Citation: Nguyen TN, Babikian VL, Romero R, Pikula A, Kase CS, Jovin TG and Norbash AM (2011) Intraarterial treatment methods in acute stroke therapy. Front. Neur. 2:9. doi: 10.3389/fneur.2011.00009

This article was submitted to Frontiers in Endovascular and Interventional Neurology, a specialty of Frontiers in Neurology. Copyright (c) 2011 Nguyen, Babikian, Romero, Pikula, Kase, Jovin and Norbash. This is an open-access article subject to an exclusive license agreement between the authors and Frontiers Media SA which permits unrestricted use, distribution, and reproduction in any medium, provided the original authors and source are credited. 


\section{APPENDIX}
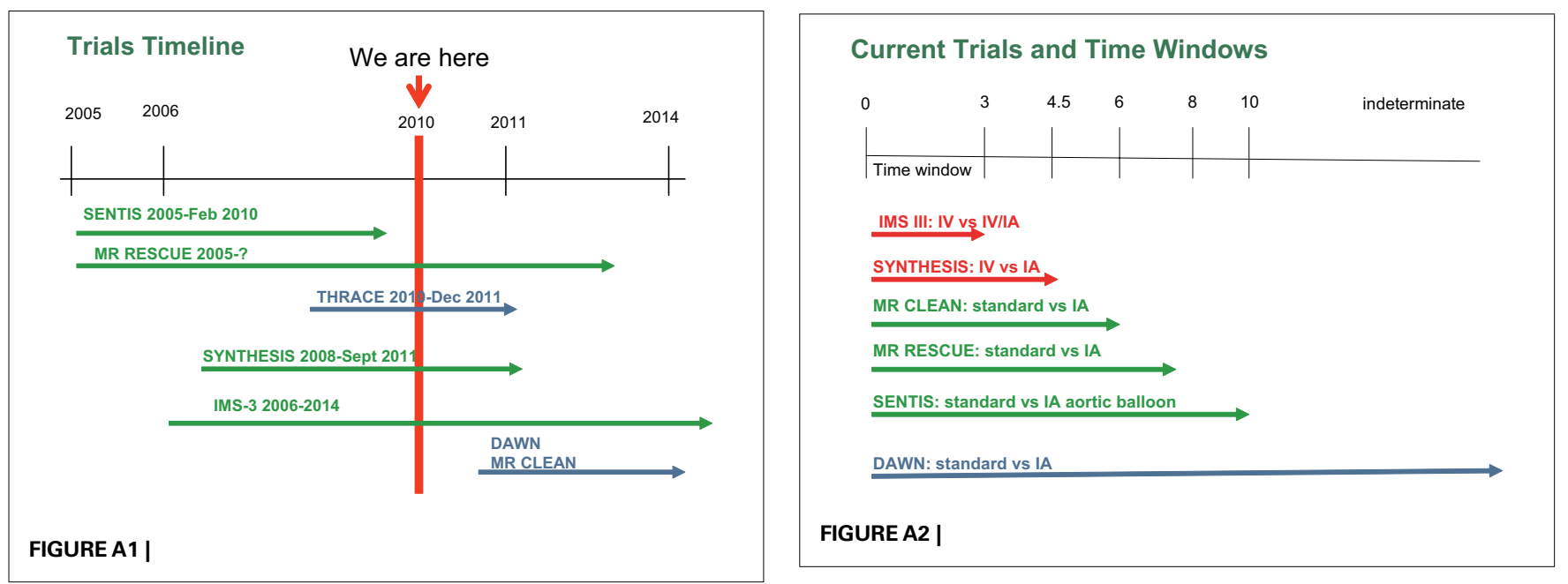